\title{
Clinical significance of provoked coronary spasm at chronic stage in patients who underwent successful complete coronary revascularization with first-generation drug-eluting stents
}

\author{
Shigenori Ito $^{1 *}$, Kosuke Nakasuka ${ }^{1}$, Satoru Sekimoto ${ }^{1}$, Kazuyuki Miyata ${ }^{1}$, Masahiko Inomata ${ }^{1}$, \\ Takayuki Yoshida $^{1}$, Nozomu Tamai ${ }^{1}$, Tomoaki Saeki ${ }^{1}$, Shin Suzuki ${ }^{1}$, Yoshimasa Murakami ${ }^{1}$, \\ Akihiro Morino $^{2}$, Yoshiyuki Shimizu ${ }^{2}$, Koichi Sato ${ }^{1}$ \\ ${ }^{1}$ Division of Cardiology, Nagoya City East Medical Center, Nagoya, Japan \\ ${ }^{2}$ Division of Clinical Engineering, Nagoya City East Medical Center, Nagoya, Japan \\ Email: ${ }^{*}$ sito@higashi-hosp.jp \\ Received 3 April 2013; revised 20 May 2013; accepted 1 June 2013 \\ Copyright (C) 2013 Shigenori Ito et al. This is an open access article distributed under the Creative Commons Attribution License, \\ which permits unrestricted use, distribution, and reproduction in any medium, provided the original work is properly cited.
}

\begin{abstract}
Background: Provoked spasm might have influence on cardiovascular events even after successful DES implantation. Methods and results: A consecutive 122 patients who underwent first-generation DES (Cypher $^{\mathrm{TM}}$, and Taxus ${ }^{\mathrm{TM}}$ ) implantation and had no residual stenosis at follow-up coronary angiography were included. All patients also underwent acetylcholine provocation test (ACh) at follow-up angiography. Age, sex, coronary risk factors (smoking, hypertension, diabetes mellitus, dyslipidemia), medication (calcium channel blockers, angiotensin receptor blockers, angiotensin converting enzyme inhibitors, nitrates, $\beta$ blockers, statins), duration from stent implantation to follow-up angiography $(15.5 \pm 14.5$ months), old myocardial infarction, Ach + were included as variables for multivariate analysis for cardiovascular events (angina pectoris without intervention, target lesion revascularization, acute myocardial infarction, definite or probable stent thrombosis, cardiac death, and stroke). ACh provocation test was positive in $64.8 \%$. The following events occurred during a mean follow-up period of $26.9 \pm 9.5$ months; angina pectoris without intervention in 12 , very late stent thrombosis in 1 , acute myocardial infarction in 1 , sudden death in 1, and stroke in 4. By Adjusted Cox hazard model, age was the independent predictor of future cardiovascular events. ACh was unbalanced data for Cox hazard model, and by logistic regression model, ACh was the strongest predictor. Conclusions:
\end{abstract}

\footnotetext{
*Corresponding author.
}

Coronary endothelial dysfunction at chronic stage is the strongest predictor of further prognosis in patients with first-generation DES.

Keywords: Drug-Eluting Stent; Follow-Up Studies; Percutaneous Coronary Intervention; Acetylcholine; Cardiovascular Event

\section{INTRODUCTION}

Due to reduced restenosis rate after drug-eluting stents (DES) implantation and improved skills, it is important to manage patients with non-stenotic coronary trees for better long-term clinical outcomes. Although endothelial dysfunction has been recognized in patients with DES [1-13], little is known about its clinical significance, especially about prognostic one. Among several DESs, the first-generation stents (Cypher $^{\mathrm{TM}}$, Cordis Corp., Miami Lakes, Florida and Taxus ${ }^{\mathrm{TM}}$, Boston Scientific, Natick, Massachusetts) have been reported most frequently as causing endothelial dysfunction [2,4,7,9,11-13]. Recently, newer DESs have been developed and have more safety data $[14,15]$. However, there are lots of patients living in the world, who had already undergone first-generation stent implantation. In addition, it is well known that atherosclerotic coronary arteries are associated with coronary spasm [16-19]. Thus patients with atherosclerotic coronary lesions might be at higher risk of coronary endothelial dysfunction after DES implantation. In many circumstances, reduced endothelial function has been shown to correlate with increased atherogenesis, as well as cardiovascular risk [20-22]. However, whether DES- 
related endothelial dysfunction produces a similar risk is not known [8]. We try to know whether acetylcholine provocation test $(\mathrm{ACh})$ induced spasm at stable stage is related to the incidence of cardiovascular events during further follow-up in Japanese patients who had been reported to possess an ethnic propensity for coronary vasospasm $[23,24]$.

\section{METHODS}

\subsection{Study Population}

A total of 122 consecutive patients who underwent ACh at follow-up angiography between February 2008 and January 2010 after percutaneous coronary intervention (PCI) with first-generation DES (Cypher ${ }^{\mathrm{TM}}$ and Taxus ${ }^{\mathrm{TM}}$ ) without residual coronary stenosis (angiographically less than $50 \%$ by visual estimation) or intra-stent restenosis (ISR) were evaluated. Follow-up coronary angiography was performed as a routine management $8-12$ months after stent implantation irrespective of symptoms, however, it was delayed in some patients due to convenience of patients.

\subsection{Acetylcholine Provocation Test}

Details of protocol of ACh provocation test was described previously [5], but briefly all anti-angina drugs were stopped 24 hours before the follow-up coronary angiography. If an angina attack occurred, sublingual nitroglycerine was administered. ACh $(20 \mu \mathrm{g}$ followed by $50 \mu \mathrm{g}$ ) was injected into the right coronary artery via a diagnostic catheter by manual injection for 30 seconds. An angiogram was obtained after each dose was administered or until an ischemic sign emerged. After the spasm was resolved, ACh $(50 \mu \mathrm{g}$ followed by $100 \mu \mathrm{g})$ was administered into the left coronary artery. Final coronary angiograms were obtained after intracoronary injection of isosorbide dinitrate (ISDN) $(2-5 \mathrm{mg})$. During an ACh provocation test, a 12-lead ECG and blood pressure were continuously monitored. If spasm induced unstable hemodynamics or unbearable chest pain, ISDN was injected without provocation of the other vessels. A positive result was defined as coronary stenosis of $>90 \%$ (total occlusion, subtotal occlusion, or severe and diffuse [25]), using the final angiogram as a reference by visual estimation along with symptoms and any ischemic ECG changes $[5,26,27]$ in at least one stent implanted vessels. Patients with positive $\mathrm{ACh}$ were treated with adequate anti-anginal drugs thereafter at the discretion of the attending doctors including at least additional calcium channel blockers.

\subsection{Evaluation of Cardiovascular Events}

Recurrence of angina pectoris without PCI defined as typical angina symptom (anterior chest pain or oppression at rest and/or during exertion) that is relieved with sublingual nitroglycerine, major cardiovascular events (MACE including all cause death, definite or probable stent thrombosis, non-fatal acute myocardial infarction, congestive heart failure, target lesion revascularization, and stroke) were evaluated by clinical charts and/or telephone contacts during follow-up. Diagnosis of angina pectoris was symptom driven not necessarily with electrocardiographic ischemic change because ECG recording during symptom was usually difficult. Stent thrombosis included only probable or definite ones according to academic research consortium (ARC) [28]. The diagnosis of acute myocardial infarction was followed by the standard universal definition [29]. Stroke included cerebral infarction and cerebral bleeding. The study was approved by the Ethics Committee of our hospital. All patients provided informed written consent.

\subsection{Statistical Analysis}

Data were expressed as the mean \pm standard deviation or number of cases. The frequencies were compared between the groups using the chi-square test or Fisher exact test as appropriate. The mean values were compared using the unpaired t test. Adjusted Cox and logistic regression models were used to associate with the cardiovascular events (all cardiovascular events including angina pectoris without need of PCI and MACE,). At first, unadjusted Cox proportional model was used for each clinical factor shown in Table 1. Then, adjusted Cox proportional hazards model was performed, with age, duration after stent implantation, and ACh test as significant predictors for cardiovascular events in Table 1. Then, DfBeta was checked for fitness of Cox regression for categorical variable. ACh test data was found to be unbalanced and an influential case caused substantial changes in the value of the coefficients when data ware computed with or without it. Thus, multiple logistic regression analysis was also performed to obtaion adjusted preditors of cardiovascular events occurred over one year (mean months \pm standard $=27.8 \pm 9.0$ ) after the follow-up coronary angiography with ACh provocation test. A confidence level of $\mathrm{p}<0.05$ was considered statistically significant. Analyses were performed with SPSS Ver. 20.0 (IBM, NY, USA).

\section{RESULTS}

\subsection{Baseline Clinical Characteristic (Table 1)}

A total of 122 patients were evaluated at $15.5 \pm 14.5$ months after DES implantation. There were several unbalanced data in clinical factors between $\mathrm{ACh}(+)$ and ACh (-) groups. Old myocardial infarction was seen more 
Table 1. Baseline clinical characteristics.

\begin{tabular}{ccccc}
\hline & Overall N=122 & ACh $(+) \mathrm{N}=79$ & ACh $(-) \mathrm{N}=43$ & p value \\
\hline Age & $68.3 \pm 9.5$ & $68.0 \pm 9.6$ & $68.8 \pm 9.6$ & 0.660 \\
Sex (Male) & $89(73.0 \%)$ & $57(72.2 \%)$ & $32(74.4 \%)$ & 0.787 \\
OMI & $23(18.9 \%)$ & $15(19.0 \%)$ & $8(18.6 \%)$ & 0.959 \\
Hypertension & $82(67.2 \%)$ & $48(60.8 \%)$ & $34(79.1 \%)$ & 0.048 \\
Diabetes Mellitus & $64(52.5 \%)$ & $35(44.3 \%)$ & $29(67.4 \%)$ & 0.014 \\
Dyslipidemia & $84(68.9 \%)$ & $53(67.1 \%)$ & $31(72.1 \%)$ & 0.636 \\
Current Smoking & $20(16.4 \%)$ & $14(17.7 \%)$ & $6(14.0 \%)$ & 0.591 \\
ISDN & $45(36.9 \%)$ & $31(39.2 \%)$ & $14(32.6 \%)$ & 0.465 \\
CCB & $72(59.0 \%)$ & $40(50.6 \%)$ & $32(74.4 \%)$ & 0.011 \\
ACEI & $34(27.9 \%)$ & $21(26.6 \%)$ & $13(30.2 \%)$ & 0.667 \\
ARB & $46(37.7 \%)$ & $26(32.9 \%)$ & $20(46.5 \%)$ & 0.139 \\
Statin & $83(68.0 \%)$ & $51(64.6 \%)$ & $32(74.4 \%)$ & 0.264 \\
$\begin{array}{c}\text { B blocker } \\
\text { Number of stented Vessels } 1 / 2 / 3\end{array}$ & $31(25.4 \%)$ & $22(27.8 \%)$ & $9(20.9 \%)$ & 0.402 \\
Duration after stent implantation & $15.5 \pm 14.5$ & $58 / 18 / 3$ & $25 / 18 / 0$ & 0.049
\end{tabular}

Abbreviations: ACh; acetylcholine provocation test, OMI; old myocardial infarction, ISDN; isosorbide dinitrate, CCB; calcium channel blocker, ACEI; angiotensin converting enzyme inhibitor, ARB; angiotension receptor blocker, MACE; major cardiovascular events.

frequently in ACh (+) group. Hypertension, use of calcium channel blockers, and diabetes mellitus were more frequent in Ach (-) group. Multiple stented vessels tended to be more frequent in Ach (-) group. There was no significant difference in any other clinical characteristics.

\subsection{Incidence of ACh Test Positive Results}

Positive rate of ACh test was $64.8 \%$ (79/122).

\subsection{Incidence of Cardiovascular Events (Table 2)}

During mean follow-up period of $27.8 \pm 9.0$ months the following events occurred; angina pectoris without PCI in 12, MACE in 7 including 1 very late stent thrombosis, 1 acute myocardial infarction, 1 sudden death, and 4 stroke. Thus, all cardiovascular events were found in a total of 19 patients. Angina pectoris without PCI occurred more frequently in $\mathrm{ACh}(+)$ than $\mathrm{ACh}(-)$ group $(12 / 79$ vs $0 / 43, P=0.008)$. Incidence of MACE was not different (ACh (+) 6/79 vs ACh (-) 1/43, p = 0.419). Incidence of all cardiovascular events were significantly higher in $\mathrm{ACh}(+)$ than in ACh (-) group (18/79 vs 1/43, $\mathrm{p}=0.003$ ).

\subsection{Unadjusted Cox Regression Analysis (Table 3) and Adjusted Cox (Table 4) and Logistic (Table 5) Regression Analysis for the Prediction of All Cardiovascular Events}

Unadjusted Cox regression analysis showed that age, duration after stent implantation were predictors of all cardiovascular events. These variables were put into adjusted Cox regression model. ACh test was unbalanced data because of one particular case, failing in showing independency. However, by adjusted logistic regression analysis revealed that $\mathrm{ACh}(+)$ result was the strongest predictor of all cardiovascular events.

\section{DISCUSSION}

In this study, we revealed that provoked coronary spasm by ACh provocation at chronic stage predicted the cardiovascular events during further follow-up period in patients with first-generation DES when residual stenosis or intra-stent restenosis was not detected.

\subsection{Coronary Endothelial Dysfunction Manifested After DES Implantation}

So far, several studies have been reported regarding the 
Table 2. Incidence of cardiovascular events during follow-up after acetylcholine provocation test.

\begin{tabular}{ccccc}
\hline & Over all N $=122$ & ACh (+) group N=79 & ACh (-) group N =43 & p value \\
\hline Follow-up period (Months) & $26.9 \pm 9.5$ & $26.2 \pm 10.1$ & $28.2 \pm 8.2$ & 0.271 \\
Angina pectoris & $12(9.8 \%)$ & $12(15.2 \%)$ & $0(0 \%)$ & 0.008 \\
MACE & $7(5.7 \%)$ & $6(7.6 \%)$ & $1(2.3 \%)$ & 0.419 \\
All events & $19(15.6 \%)$ & $18(22.8 \%)$ & $1(2.3 \%)$ & 0.003 \\
\hline
\end{tabular}

Abbreviations: ACh; acetylcholine provocation test, MACE; major cardiovascular events.

Table 3. Predictors of cardiovascular events after first-generation drug-eluting stent implantation (Unadjusted Cox regression analysis).

\begin{tabular}{|c|c|c|c|c|}
\hline & Hazard ratio & & & $\mathrm{p}$ value \\
\hline Age (1 year increment) & 1.06 & 1.01 & 1.12 & 0.012 \\
\hline Sex (Male) & 0.41 & 0.16 & 1.02 & 0.055 \\
\hline OMI & 0.20 & 0.03 & 1.48 & 0.114 \\
\hline Hypertension & 0.70 & 0.28 & 1.74 & 0.441 \\
\hline Diabetes Mellitus & 1.49 & 0.59 & 3.80 & 0.398 \\
\hline Dyslipidemia & 0.60 & 0.24 & 1.49 & 0.269 \\
\hline Current Smoking & 1.03 & 0.30 & 3.53 & 0.965 \\
\hline ISDN & 2.24 & 0.91 & 5.54 & 0.079 \\
\hline $\mathrm{CCB}$ & 0.50 & 0.20 & 1.24 & 0.135 \\
\hline ACEI & 0.72 & 0.24 & 2.16 & 0.555 \\
\hline ARB & 1.98 & 0.81 & 4.89 & 0.136 \\
\hline Statin & 0.82 & 0.32 & 2.07 & 0.669 \\
\hline$\beta$ blocker & 0.76 & 0.25 & 2.28 & 0.622 \\
\hline \multicolumn{5}{|l|}{ Number of stented Vessels } \\
\hline 1 & & & & 0.933 \\
\hline 2 & 0.82 & 0.30 & 2.29 & 0.710 \\
\hline 3 & 0.00 & 0.00 & & 0.982 \\
\hline Duration after stent implantation & 1.03 & 1.01 & 1.06 & 0.012 \\
\hline ACh test positive & 11.38 & 1.52 & 85.35 & 0.018 \\
\hline
\end{tabular}

Abbreviations: same as in Table 1.

Table 4. Adjusted predictors of cardiovascular events after first-generation drug-eluting stent implantation (Cox regression model).

\begin{tabular}{ccccc}
\hline Cox hazard model & Adjusted Hazard ratio & & $95.0 \%$ CI & \multicolumn{2}{c}{ p value } \\
\hline Age (1 increment) & 1.093 & 1.032 & 1.158 & 0.003 \\
Duration after stent implantation & 1.019 & 0.974 & 1.066 & 0.410 \\
ACh test positive & & & & \\
\hline
\end{tabular}

* DfBeta was checked for fitness of Cox regression. ACh data was unbalanced data and an influential case caused substantial changes in the value of the coefficients when data ware computed with or without the case. 
Table 5. Adjusted predictors of cardiovascular events after first-generation drug-eluting stent implantation (Multiple logistic regression model).

\begin{tabular}{ccccc}
\hline Multiple logistic regression model & Adjusted Odds ratio & \multicolumn{2}{c}{$95.0 \%$ CI } & \multicolumn{2}{c}{ p value } \\
\hline Age (1 increment) & 1.103 & 1.029 & 1.181 & 0.005 \\
ACh test positive & 12.671 & 1.544 & 104.001 & 0.018 \\
Duration after stent implantation & 1.01 & 0.97 & 1.052 & 0.637 \\
\hline
\end{tabular}

endothelial dysfunction after DES implantation especially in the segments distal to the implanted stents [1-12, 30]. According to the results of reports from Asian countries $[2,5,7,13,31]$ the manifestation of coronary vasoconstriction induced by exercise or ACh provocation seemed to be stronger compared with that from European countries $[4,11,12]$. This might be related to the ethnic propensity of vasospastic angina pectoris. Although this phenomenon should be reminded in the treatment of patients who received DES implantation, its clinical significance has not been well elucidated. According to our previous study [5], the vasoconstriction may occur silently in almost half of candidates of ACh provocation test similarly to the study of variant angina pectoris in Japan [32].

\subsection{Association of Atherosclerosis with Coronary Spasm}

On the other hand, coronary spasm may occur in patients with coronary atherosclerosis without stent implantation [16-19]. The incidence has been reported as high as $66.7 \%$. Thus, some patients have the possibility of coronary vasospasm before the DES implantation. Generally speaking, because these patients have severe stenosis, $\mathrm{ACh}$ provocation test can not be adopted routinely because of safety issue in most cases without such cases as strongly suspected coronary spastic angina. In real-world patients, actually such patients registered in this study, coronary endothelial dysfunction must be a combination of intrinsic and DES-induced ones. If ACh provocation test can be performed both before DES implantation and at chronic stage, the discrimination could be possible.

\subsection{Suspected Mechanism of Relationship between Provoked Coronary Spasm and Cardiovascular Events in Patients with DES}

Although we must limit the results only for about twoyear follow-up duration, the cardiovascular events were strongly associated with $\mathrm{ACh}$ positive results at chronic stage without residual stenosis or in-stent restenosis. Almost ACh (-) patients could live well without events. Although we can not specify how the dysfunction is related to the cardiovascular events, however delayed reendothelialization and/or coronary endothelial dysfunc- tion might have been led to the stent thrombosis [33]. Coronary vasoconstriction or spasm would result in reduction of coronary blood flow and deterioration of nonlaminar flow within the stented vessel, which may be associated with an increase in inflammation and thrombosis [34] The prognosis of patients who have coronary vasospastic angina have been also reported [21,35]. These results can be partially applied for patients in this study. Interventional cardiologists should not forget this fact even after they had succeeded in complete revascularization and control of angina pectoris. Furthermore, $\mathrm{ACh}$ provocation test might be useful in predicting cardiovascular events.

\subsection{Delayed Arterial Healing of First-Generation Stents and Prognosis}

Hallmarks of delayed arterial healings are composed of late fibrin deposition, delayed or absent re-endothelialization, chronic arterial wall inflammation, and persistent platelet activation. Late stent thrombosis may be more frequently related to incomplete healing and/or inadequate neointimal coverage. Serial angioscopic or optimal coherence tomography examinations, and evaluation at autopsy suggest that stent endothelialization is delayed or incomplete in DES [33]. On the other hand, the physical presence of endothelial coverage may not confer functional integrity, and chronic vascular/endothelial dysfunction may contribute to very late stent thrombosis [33]. The relationship between stent strut imamture endothelialization and arterial dysfunction in the segments distal and far distal to the implanted stents has not been well clarified. However, these could be related to the future cardiovascular events long after DES implantation.

\subsection{Angina Pectoris after DES Implantation}

Angina pectoris without PCI occurred more frequently in $\mathrm{ACh}(+)$ than ACh $(-)$ group $(12 / 79$ vs $0 / 43, \mathrm{p}=0.008)$. Patients with ACh $(+)$ results at follow-up coronary angiography were prescribed calcium channel blocker and/ or other anti-angina drugs during further follow-up period in almost all cases. Even this fact angina pectoris, probably coronary spastic angina occurred more frequently in patients with $\mathrm{ACh}(+)$. This means that there is 
a possibility that earlier exposure of calcium channel blockers at the time of DES implantation would be effective in preventing coronary vasospasm because incidence of $\mathrm{CCB}$ use was more frequently in $\mathrm{ACh}(-)$ patients similar to cases in patients with coronary spastic angina pectoris. In fact, Tsuburaya et al reported the suppressive effect of long acting nifedipine for coronary hyperconstricting responses induced by paclitaxel-eluting stents in pigs in vivo [36]. In humans, in ENCORE (Evaluation of Nifidipine and Cerivastatin on Recovery of coronary Endothelial function) I [37] and II [38] study, nifeidipine was reported to improve coronary endothelial function in patients who underwent PCI, although DES was not used in these studies.

\subsection{Limitations}

This study has several limitations. First, this is a single center observational study with small sample size and not a randomized study. There was unbalanced data in the clinical characteristics between groups with positive and negative results of $\mathrm{ACh}$ provocation test at chronic stage. Thus, we conducted multivariate analyses to find out independent predictors of cardiovascular events after first-generation DES implantation. Second, anti hypertenstive and anginal drugs might have affected the results of coronary spasm provocation test. Although all patients stopped anti-anginal and anti-hypertensive drugs at least 24 hours before Ach provocation test, the withdrawal duration might not have been enough in some drugs. Third, ACh provocation test was not performed before DES implantation as a protocol. Thus, as we discuss, the coronary spasm induced by $\mathrm{ACh}$ would be rendered as combination of intrinsic and DES-induced. Fourth, time from stent implantation to follow-up coronary angiography was not determined prospectively. Patients who underwent DES implantation at the other hospitals were included, and information about stent procedures was tried to obtain from the index hospital. Lastly, in terms of predicting cardiovascular events, hard end points, such as MACE was not significant.

\section{CONCLUSION}

Acetylcholine-induced coronary spasm might have the clinical significance from the stand point of future cardiovascular events in patients who underwent successful PCI without residual stenosis or in-stent restenosis at chronic stage.

\section{REFERENCES}

[1] Azar, R.R. (2010) Diffuse coronary spasm in a patient with a recent stent. JACC: Cardiovascular Interventions, 3, 459-460. doi:10.1016/j.jcin.2009.11.023
[2] Fuke, S., Maekawa, K., Kawamoto, K., Saito, H., Sato, T., Hioka, T. and Ohe, T. (2007) Impaired endothelial vasomotor function after sirolimus-eluting stent implantaion. Circulation Journal, 71, 220-225. doi:10.1253/circj. 71.220

[3] Hamilos, M., Sarma, J., Ostojic, M., Cuisset, T., Sarno, G., Melikian, N., Ntalianis, A., Muller, O., et al. (2008) Interference of drug-eluting stents with endothelium-dependent coronary vasomotion: Evidence for device-specific responses. Circulation: Cardiovascular Interventions, 1, 193-200. doi:10.1161/CIRCINTERVENTIONS.108.797928

[4] Hofma, S.H., Van Der Giessen, W.J., Van Dalen, B.M., Lemos, P.A., McFadden, E.P., Sianos, G., Lighhart, J.M. R., Van Essen, D., et al. (2006) Indication of long-term endothelial dysfunction after sirolimus-eluting stent implantation. European Heart Journal, 27, 166-170. doi:10.1093/eurheartj/ehi571

[5] Ito, S., Nakasuka, K., Morimoto, K., Inomata, M., Yoshida, T., Tamai, N., Suzuki, S., Murakami, Y., et al. (2011) Angiographic and clinical characteristics of patients with acetylcholine-induced coronary vasospasm on follow-up coronary angiography following drug-eluting stent implantation. Journal of Invasive Cardiology, 23, 57-64.

[6] Jabs, A., Gobel, S., Wenzel, P., Kleschyov, A.L., Hortmann, M., Oelze, M., Daiber, A. and Munzel, T. (2008) Sirolimus-induced vasomotor dysfunction Increased mitochondrial and nicotinamide adenosine dinucleotide phosphate oxidase-dependent superoxide production and decreased vascular nitric oxide formation. Journal of the American College of Cardiology, 51, 2130-2138. doi:10.1016/j.jacc.2008.01.058

[7] Kim, J.W., Suh, S.Y., Choi, C.U., Na, J.O., Kim, E.J., Rha, S.W., Park, C.G., Seo, H.S., et al. (2008) Six-month comparison of coronary endothelial dysfunction associated with sirolimus-eluting stent versus paclitaxel-eluting stent. JACC: Cardiovascular Interventions, 1, 65-71. doi:10.1016/j.jcin.2007.11.002

[8] Muhlenstein, J.B. (2008) Endothelial dysfunction associated with drug-eluting stents. Journal of the American College of Cardiology, 51, 39-40.

[9] Shin, D.I., Kim, P.J., Seung, K.-B., Kim, D.B., Kim, M.-J., Chang, K., Lim, S.M., Jeon, D.S., et al. (2007) Drug-eluting stent implantation could be asscoiated with long-term coronary endothelial dysfunction comparison between sirolimus-eluting stent and paclitaxel-eluting stent. International Heart Journal, 48, 553-567. doi:10.1536/ihj.48.553

[10] Shiroto, T., Yasuda, S., Tsuburaya, R., Ito, Y., Takahashi, J., Ito, K., Ishibashi-Ueda, H., Shimokawa, H. (2009) Role of Rho-Kinase in the pathogenesis of coronary hyperconstricting responses induced by drug-eluting stents in pigs in vivo. Journal of the American College of Cardiology, 54, 2321-2329. doi:10.1016/j.jacc.2009.07.045

[11] Togni, M., Raber, L., Cocchia, R., Wenaweser, P., Cook, S., Windecker, S., Meier, B., Hess, O.M. (2007) Local vascular dysfunction after coronary paclitaxel-eluting 
stent implantaion. International Journal of Cardiology, 120, 212-220.

doi:10.1016/j.ijcard.2006.09.021

[12] Togni, M., Windecker, S., Cocchia, R., Wenaweser, P., Cook, S., Billinger, M., Meier, B. and Hess, O.M. (2005) Sirolimus-eluting stents associated with paradoxic coronary vasoconstriction. Journal of the American College of Cardiology, 46, 231-236. doi:10.1016/j.jacc.2005.01.062

[13] Maekawa, K., Kawamoto, K., Fuke, S., Yoshioka, R., Saito, H., Sato, T. and Hioka, T. (2006) Severe endothelial dysfunction after sirolimud-eluting stent implantation. Circulation, 113, e850-e851. doi:10.1161/CIRCULATIONAHA.105.597948

[14] Hofma, S.H., Brouwer, J., Velders, M.A., Van't Hof, A.W., Smits, P.C., Quere, M., de Vries, C.J. and Van Boven, A.J. (2012) Second-generation everolimus-eluting stents versus first-generation sirolimus-eluting stents in acute myocardial infarction: 1-year results of the randomized XAMI (xiencev stent vs. cypher stent in primary PCI for acute myocardial infarction) trial. Journal of the American College of Cardiology, 60, 381-387. doi:10.1016/j.jacc.2012.01.073

[15] Palmerini, T., Kirtane, A.J., Serruys, P.W., Smits, P.C., Kedhi, E., Kereiakes, D., Sangiorgi, D., Bacchi Reggiani, L., et al. (2012) Stent thrombosis with everolimus-eluting stents: Meta-analysis of comparative randomized controlled trials. Circulation: Cardiovascular Interventions, 5, 357-364.

doi:10.1161/CIRCINTERVENTIONS.111.967083

[16] Bertrand, M.E., LaBlanche, J.M., Tilmant, P.Y., Thieuleux, F.A., Delforge, M.R., Carre, A.G., Asseman, P., Berzin, B., et al. (1982) Frequency of provoked coronary arterial spasm in 1089 consecutive patients undergoing coronary arteriography. Circulation, 65, 1299-1306. doi:10.1161/01.CIR.65.7.1299

[17] Curry, R.C.J., Pepine, C.J., Sabom, M.B., Feldman, R.L., Christie, L.G. and Conti, C.R. (1977) Effects of ergonovine in patients with and without coronary artery disease. Circulation, 56, 803-809. doi:10.1161/01.CIR.56.5.803

[18] Okumura, K., Yasue, H., Matsuyama, K., Ogawa, H., Morikami, Y., Obata, K. and Sakaino, N. (1992) Effect of acetylcholine on the highly stenotic coronary artery: Difference between the constrictor response of the infarctrelated artery and that of the noninfarct-related artery. Journal of the American College of Cardiology, 19, 752758. doi:10.1016/0735-1097(92)90513-M

[19] Tanabe, Y., Itoh, E., Suzuki, K., Ito, M., Hosaka, Y., Nakagawa, I. and Kumakura, M. (2002) Limited role of coronary angioplasty and stenting in coronary spastic angina with organic stenosis. Journal of the American College of Cardiology, 39, 1120-1126. doi:10.1016/S0735-1097(02)01746-1

[20] Schachinger, V., Britten, M.B. and Zeiher, A. (2000) Impaired epicardial coronay vasoreactivity predicts for adverse cardiovascular events during long-term follow up. Circulation, 101, 1899-1906. doi:10.1161/01.CIR.101.16.1899

[21] Egashira, K., Kikuchi, Y., Sagara, T., Sugihara, M. and
Nakamura, M. (1987) Long-term prognosis of vasospastic angina without significant atherosclerotic coronary artery disease. Japanese Heart Journal, 28, 841-849. doi:10.1536/ihj.28.841

[22] Nakamura, M., Takeshita, A. and Nose, Y. (1987) Clinical characteristics associated with myocardial infarction, arrhythmia, and sudden death in patients with vasospastic angina. Circulation, 75, 1110-1116. doi:10.1161/01.CIR.75.6.1110

[23] Beltrame, J.F., Sasayama, S. and Maseri, A. (1999) Racial heterogeneity in coronary artery vasomotor reactivity: Differences between Japanese and Caucasian patients. Journal of the American College of Cardiology, 33, 1442-1452. doi:10.1016/S0735-1097(99)00073-X

[24] Pristipino, C., Beltrame, J.F., Finocchiaro, M.L., Hattori, R., Fujita, M., Mongiardo, R., Cianflone, D., Sanna, T., et al. (2000) Major racial differences in coronary constrictor response between Japanese and Caucasians with recent myocardial infarction. Circulation, 101, 1102-1108. doi:10.1161/01.CIR.101.10.1102

[25] Katoh, D., Mizuno, Y., Harada, E., Ito, T., Morikawa, Y., Nakagawa, H., Saito, Y., Yoshimura, M., et al. (2012) High incidence of provoked coronary spasm in the presence of a stent after myocardial infarction: Therapeutic and prognostic implications. Coronary Artery Disease, 23, 141-145. doi:10.1097/MCA.0b013e32835115ee

[26] Sueda, S., Ochi, N., Kawada, H., Matsuda, S., Hayashi, Y., Tsuruoka, T. and Uraoka, T. (1999) Frequency of provoked coronary vasospasm in patients undergoing coronary angiography with spasm provocation test of acetylcholine. American Journal of Cardiology, 83, 1186-1190. doi:10.1016/S0002-9149(99)00057-0

[27] Yasue, H., Horio, Y., Nakamura, N., Fujii, H., Imoto, N., Sonoda, R., Kugiyama, K., Obata, K., et al. (1986) Induction of coronary artery spasm by acetylcholine in patients with variant angina: Possible role of the parasympathetic nervous system in the pathogenesis of coronary artery spasm. Circulation, 74, 955-963. doi:10.1161/01.CIR.74.5.955

[28] Cutlip, D.E., Windecker, S., Mehran, R., Boam, A., Cohen, D.J., Van Es, G.A., Steg, P.G., Morel, M.A., et al. (2007) Clinical end points in coronary stent trials: A case for standardized definitions. Circulation, 115, 2344-2351. doi:10.1161/CIRCULATIONAHA.106.685313

[29] Thygesen, K., Alpert, J.S., Jaffe, A.S., Simoons, M.L., Chaitman, B.R., White, H.D., Katus, H.A., Apple, F.S., et al. (2012) Third universal definition of myocardial infarction. Journal of the American College of Cardiology, 60, 1581-1598. doi:10.1016/j.jacc.2012.08.001

[30] Minami, Y., Kaneda, H., Inoue, M., Ikutomi, M., Morita, T. and Nakajima, T. (2012) Endothelial dysfunction following drug-eluting stent implantation: A systematic review of the literature. International Journal of Cardiology, 165, 222-228.

[31] Kim, J.W., Seo, H.S., Park, J.H., Na, J.O., Choi, C.U., Lim, H.E., Kim, E.J., Rha, S.-W., et al. (2009) A prospective randomized, 6-month comparison of the coronary vasomotor response associated with a zotarolimus- 
versus a sirolimus-eluting stent. Journal of the American College of Cardiology, 53, 1653-1659. doi:10.1016/j.jacc.2009.01.051

[32] Egashira, K., Araki, H., Takeshita, A. and Nakamura, M. (1989) Silent myocardial ischemia in patients with variant angina. Japanese Circulation Journal, 53, 1452-1457. doi: $10.1253 /$ jcj.53.1452

[33] Holmes, Jr., D.R., Kereiakes, D.J., Garg, S., Serruys, P.W., Dehmer, G.J., Ellis, S.G., Williams, D.O., Kimura, T., et al. (2010) Stent thrombosis. Journal of the American College of Cardiology, 56, 1357-1365. doi:10.1016/j.jacc.2010.07.016

[34] Hamasaki, S. and Tei, C. (2011) Effect of coronary endothelial function on outcomes in patients undergoing percutaneous coronary intervention. Journal of Cardiology, 57, 231-238. doi:10.1016/j.jjcc.2011.02.003

[35] Shimokawa, H., Nagasawa, K., Irie, T., Egashira, S., Egashira, K., Sagara, T., Kikuchi, Y. and Nakamura, M. (1988) Clinical characteristics and long-term prognosis of patients with variant angina. A comparative study between western and Japanese populations. International Journal of Cardiology, 18, 331-349. doi:10.1016/0167-5273(88)90052-6
[36] Tsuburaya, R., Yasuda, S., Shiroto, T., Ito, Y., Gao, J.Y., Aizawa, K., Kikuchi, Y., Ito, K., et al. (2012) Long-term treatment with nifedipine suppresses coronary hyperconstricting responses and inflammatory changes induced by paclitaxel-eluting stent in pigs in vivo: possible involvement of Rho-kinase pathway. European Heart Journal, 33, 791-799. doi:10.1093/eurheartj/ehr145

[37] ENCORE Investigators (2003) Effect of nifedipine and cerivastatin on coronary endothelial function in patients with coronary artery disease: The ENCORE I study (Evaluation of nifedipine and cerivastatin on recovery of coronary endothelial function). Circulation, 107, 422-428. doi:10.1161/01.CIR.0000046488.52939.BF

[38] Luscher, T.F., Pieper, M., Tendera, M., Vrolix, M., Rutsch, W., Van Den Branden, F., Gil, R., Bischoff, K. O., et al. (2009) A randomized placebo-controlled study on the effect of nifedipine on coronary endothelial function and plaque formation in patients with coronary artery disease: The ENCORE II study. European Heart Journal, 30, 1590-1597. doi:10.1093/eurheartj/ehp151 